\title{
EHBRECHT, Wilfried, Konsens und Konflikt. Skizzen und Überlegungen zur älteren Verfassungsgeschichte deutscher Städte
}

Pierre Monnet

\section{OpenEdition}

\section{Journals}

Édition électronique

URL : http://journals.openedition.org/ifha/1160

DOI : 10.4000/ifha. 1160

ISSN : 2198-8943

Éditeur

IFRA - Institut franco-allemand (sciences historiques et sociales)

Référence électronique

Pierre Monnet, «EHBRECHT, Wilfried, Konsens und Konflikt. Skizzen und Überlegungen zur älteren Verfassungsgeschichte deutscher Städte », Revue de l'IFHA [En ligne], Date de recension, mis en ligne le 01 janvier 2002, consulté le 22 septembre 2020. URL : http://journals.openedition.org/ifha/1160 ; DOI : https://doi.org/10.4000/ifha.1160

Ce document a été généré automatiquement le 22 septembre 2020.

(CIFHA 


\title{
EHBRECHT, Wilfried, Konsens und Konflikt. Skizzen und Überlegungen zur älteren Verfassungsgeschichte deutscher Städte
}

\author{
Pierre Monnet
}

1 Les spécialistes d'histoire urbaine connaissent bien cette collection intitulée " Städteforschung ", série reconnaissable à sa couverture brune, éditée par l'institut d'histoire urbaine comparée de Münster (voir sa présentation dans BullMHFA, 37, 2001, p. 133-135).

2 Le premier ouvrage pose la question des bases politiques, philosophiques et juridiques de l'idée d'égalité entre les citoyens d'une communauté urbaine au Moyen Âge. L'auteur part d'abord du constat paradoxal suivant lequel l'historiographie moderne, spécialement celle du positivisme bourgeois du XIXe s., avait érigé la ville médiévale en îlot de modernité et d'égalité dans un océan de féodalité et de rapports inégaux de force ; alors que tout porte à croire que jamais les citadins même des XIIe-XVe s ne sont perçus ainsi, ni dans les chroniques ni dans les textes normatifs dont l'historien dispose. Et pourtant, l'aequalitas, la paritas, furent une revendication constante des révoltes citadines, une exigence sans cesse rappelée par l'Église, une mesure érigée par les philosophes et les théologiens en horizon de la vie en communauté. De cette manière, elle apparaît bien comme une composante fondamentale de ce principe d'ordre de base de la société médiévale que fut le Bien Commun et dont on peut regretter que l'auteur n'en ait pas assuré une meilleure articulation au concept de son étude. On saura gré en revanche à B.F. d'avoir mené une étude de sémantique historique très neuve et stimulante sur l'évolution du couple notionnel arm/reich dans les sources entre 1150 et 1500 , couple qu'elle observe du point de vue de sa force spirituelle et biblique (associée ainsi à de nombreuses hérésies de portée sociale en Europe, du wyclifisme au hussisme), mais qu'elle observe également à l'aune de son " efficace " politique, en termes de chartes de privilège, de constitution du Conseil, de 
régime fiscal, de politique hospitalière et caritative, d'ordonnances somptuaires et de police. La revendication d'égalité, que l'on ne saurait comprendre au sens politique moderne du terme car elle ne s'appuie pas au Moyen Âge sur la définition de la liberté, occupe bien une fonction sociale, servant à réguler avant tout les relations et les comportements entre les groupes et les personnes au sein de la société urbaine. À l'image du Bien Commun, dont nous pensons qu'elle dérive en vérité, l'exigence d'égalité sert à la fois à ouvrir et à clore les conflits urbains, tels qu'observés à Spire et à Constance au cours du XIVe s. On regrettera ici de ne pas mieux voir formulée la manière dont l'idée d'égalité civique peut être mobilisée, par les élites qui restent en place, au service d'un retour à l'ordre pas plus égalitaire qu'avant le déclenchement de la crise. En d'autres termes, on aurait aimé voir l'idéologie si bien détaillée du principe d'égalité confrontée à la réalité du partage et de l'exercice du pouvoir au sein de la ville médiévale. Cet exercice aurait alors conduit l'auteur à ouvrir un peu chronologiquement son sujet et à intégrer l'étude des troubles urbains du XVe s. dont le paroxysme n'est pas étranger à une radicalisation qui, au XVIe s., trouvera pour une part son expression dans la Réforme et l'intervention extérieure des princes dans les affaires urbaines, qui constitueront l'une et l'autre un renversement complet du principe d'égalité (pas plus " moderne " pour autant !) que justement la ville tardomédiévale n'était finalement pas parvenue à mettre en place. Il n'en demeure pas moins que l'on retiendra de la démonstration l'idée selon laquelle la notion d'égalité entre citoyens continue en 1500 de dériver de la pensée chrétienne et non pas d'une théorie politique moderne et « laïque » de la civitas/civilitas. La ville médiévale, et l'on suivra l'auteur sur cette pente, continuait de chercher à appliquer le modèle de la societas christiana (la parité entre amis) et non à inventer une nouvelle éthique de vie ou d'organisation politique qui annoncerait déjà la modernité des sociétés libérales et « égalitaires".

3 Le second volume tranche dans la collection jusqu'à présent constituée pour l'essentiel de monographies et actes de colloques, puisqu'il regroupe le meilleur des articles publiés depuis 1974 par W.E., grand spécialiste des villes médiévales allemandes, particulièrement de l'espace hanséatique, et bien connu pour ses travaux sur les conflits urbains. Le recueil des articles choisis s'ordonne autour de trois pôles balançant entre consensus et conflit pour reprendre le titre de l'ouvrage : le premier qui touche à la cohabitation des groupes sociaux en ville, le second qui traite plus spécifiquement des conflits dans les cités du Nord de l'Empire entre 1300 et 1520, le dernier enfin qui pose la question de l'identité urbaine. En dépit d'une forme différente, le recueil présente plusieurs points communs avec le livre de B.F. (qui cite d'ailleurs abondamment W.E.) en matière de fondements de l'idéologie citadine médiévale.

4 Le premier ensemble prend donc pour objet d'étude les regroupements sociaux au sein de l'espace urbain qui, de tous les lieux de la société médiévale, est celui qui fait cohabiter le plus grand nombre d'activités et de conditions. La thèse majeure est celle d'un ensemble de regroupements, de solidarités et de conjurations (guildes, confréries, sociétés d'élite) dont le but est la préservation de la paix urbaine qui repose sur le pacte civique d'une part et sur la conscience que les groupes ont d'autre part et d'eux-mêmes et de leur place au sein de la communauté civique de paix, laquelle trouve aussi son prolongement dans des ligues plus ou moins lâches et formelles qui combinent à la fois la petite région (villes de Saxe) et le cercle plus diffus et variable de la Hanse. Il revient en particulier aux élites dirigeantes d'assurer cette double paix, sociale dans les murs et interurbaine au-delà dans un jeu compliqué avec les pouvoirs territoriaux princiers. 
C'est bien pourquoi la deuxième et plus importante partie du recueil s'intéresse aux nombreux conflits qui éclatèrent dans les villes septentrionales aux deux siècles finaux du Moyen Âge (Brunswick, Erfurt, Halberstadt, Soest). Le conflit y est ici présenté comme une mise à l'épreuve de tout le système urbain et non comme une attaque de nature sociale et économique contre les seules couches dirigeantes. De cette mise à l'épreuve sort une refondation du pacte communautaire, souvent au bénéfice des mêmes élites certes mais qui doivent tenir compte de la fragilité et de la complexité de l'édifice social qui leur est ainsi rappelé à l'esprit, souvent d'ailleurs par l'Église et les clercs (et c'est une des grandes originalités de la démonstration que de réhabiliter le rôle du clergé et des ordres urbains dans le processus des révoltes et du retour à la paix qui est toujours une forme ritualisée de paix de Dieu...). L'un des moyens de règlement des conflits d'une part et de prolongation du pacte citadin de l'autre fut l'orchestration d'une mémoire propre à la ville, jouant des référents locaux, régionaux et impériaux dans une combinatoire riche et variée, et réactualisée par les processions, les bannières, les cloches, le culte des saints patrons, la rédaction de chroniques urbaines. C'est sur ce chapitre que le livre, recueil dont la cohérence fait croire après coup à un véritable ouvrage, est le plus court et demanderait d'autres prolongements . 